\title{
ADIPOBIOLOGY OF OBSTRUCTIVE SLEEP APNEA SYNDROME
}

\author{
Gülnur Ozturk' ${ }^{1}$ Mevlut Yaprak², Elif Ezgi Gurel ${ }^{2}$, Keremcan Ural², Berna Tuncer ${ }^{1}$, and Levent Ozturk² \\ 'Trakya University Faculty of Health Sciences, Department of Physiotherapy and Rehabilitation, Edirne, Turkey, \\ and ${ }^{2}$ Trakya University Faculty of Medicine, Department of Physiology, Edirne, Turkey
}

\section{Abstract}

Obstructive sleep apnea (OSA) syndrome has emerged as a major public health problem because of its high prevalence amongst middle-aged, obese men as well as in lean individuals and women. It has been suggested that obesity's role in the genesis of sleep apnea is rather through its metabolic activity than a purely anatomic/mechanical impact. Recent studies demonstrate that circulating levels of adipokines, adipose tissue-derived secretory proteins, are altered in patients with OSA syndrome. For instance, leptin level is increased, whereas that of adiponectin decreased in OSA, and these changes can be reversed by treatment of apnea/hypopnea episodes. Adipokine profile seems to change towards a proinflammatory pattern that may also contribute to OSA-related cardiometabolic diseases. The mechanisms of adipose dysfunction in OSA includes hypoxia, oxidative stress and increased sympathetic nervous activity, including alterations in the circulating levels of the neurotrophins nerve growth factor (NGF) and brain-derived neurotrophic factor (BDNF). In effect, reversing hypoxia and attenuating oxidative stress and inflammation through adipokine- and NGF/BDNFtargeted pharmacology may provide novel therapeutic opportunities in patients with OSA syndrome.

Adipobiology 2014; 6: 23-29

Keywords: adipokines, adiponectin, BDNF, hypoxia, inflammation, leptin, NGF

Received 2 December 2014, revised 16 December 2014, accepted 17 December 2014. Correspondence: Prof. Levent Ozturk, Trakya Universitesi Tip Fakültesi, Fizyoloji Anabilim Dalı, 22030 Edirne, Turkey. Phone: +90 284235 7641, Fax: +90 284235 7652, E-mail: leventozturk@trakya.edu.tr

\section{Introduction}

Obstructive sleep apnea (OSA) syndrome is characterized by recurrent episodes of partial (hypopnea) or complete interruption (apnea) in breathing during sleep due to airway collapse in the pharyngeal region. Obstructive sleep apnea and its cardiometabolic consequences have been widely explored in many studies. Briefly, OSA has emerged as a major public health problem because of its high prevalence amongst middleaged, obese men as well as in lean individuals and women. Although sleep apnea has been almost always treated as a local obstruction of the upper airways, its systemic aspects in terms of cardiometabolic consequences are now acknowledged. Recently, a number of associated features of OSA have led researchers to consider the possibility that sleep apnea is a manifestation of the metabolic syndrome (dyslipidemia, dyscoagulation, hypertension and insulin resistance) and its cardiovascular sequelae (1). Interestingly, it has been suggested that obesity's role in the genesis of OSA is rather through its metabolic activity than a 
purely anatomic/mechanical impact (2).

Human body comprises two major types of adipose tissue namely brown and white adipose tissue (BAT and WAT, respectively). White adipose tissue serves as the main energy reservoir and the source of protein signaling molecules collectively termed adipokines (reviewed in 3-5, 7), whereas BAT is specialized for heat production by non-shivering thermogenesis. Over the past two decades, our understanding of the physiology of WAT changed by definition of its secretory products which are collectively termed adipokines. Among them, there are cytokines such as leptin, tumour necrosis factor-alpha (TNF- $\alpha$ ) and interleukins, also various growth factors. Adipokines also include proteins involved in the regulation of lipid and glucose homeostasis (adiponectin, TNF- $\alpha$, resistin, retinol binding protein, NGF, BDNF), blood pressure (renin, angiotensin), vascular hemostasis (plasminogen activator inhibitor-1) and angiogenesis (vascular endothelial growth factor, NGF).

Data from translational and clinical studies support the notion that OSA is associated with altered circulating levels of adipokines. It is also well established that obesity is a leading pathophysiologic factor of OSA. Accordingly, impaired adipose tissue physiology may be the link between OSA and its cardiometabolic consequences.

The present review will focus on endocrine and paracrine signals generated by adipose tissue cells (adipocytes and associated stromal vascular cells), with special reference to their possible involvement in the pathobiology of OSA syndrome.

\section{Adipocytes and other adipose cells are examples of en- docrine cells}

Adipocytes continue their lives within a connective tissue matrix and are adapted to store and release energy. The diameter of an adipocyte may vary from 20 to $200 \mu \mathrm{m}$. The nucleus is pushed to the periphery of the cell, as approximately $90 \%$ of the cell volume comprises of lipid droplets (liposomes). In the past, the adipocyte has been considered to be only a passive tissue for the storage of excess energy in the form of fat droplets. However, we now know that WAT is a central player of a communicative team broadcasting autocrine, paracrine, and endocrine signals (reviewed in 3-5). Besides its major role in regulating energy balance, WAT also plays a dynamic role in other physiological processes including inflammation, immunity, angiogenesis, haemostasis, reproduction, and memory and learning. Following the identification of leptin encoded in $o b / o b$ gene of white adipocytes (6), a critical change occurred in perspective on the physiological role of WAT. Up to now, more than 200 different adipocyte-derived secretory molecules are identified (7). In a quantitative manner, the most important secretion of adipocytes is fatty acids, of which there is a considerable amount of net release at times of negative energy balance, particularly fasting and during acute exposure to cold. Other adipokines may be classified as cytokines (leptin, TNF IL-1 $_{\mathrm{b}}$, IL-6, IL-10, TGF, IL-17, IL-18); acute phase proteins such as C-reactive protein (CRP), haptoglobin, serum amyloid A; metabolism- and inflammation-related mediators (adiponectin, visfatin, resistin, NGF, BDNF) (3-7).

\section{Adipokines and obstructive sleep apnea Leptin}

In the beginning of 2000s, several studies reported increased leptin levels in OSA patients (8-10). The severity of OSA was associated with increasing levels of leptin, and the positive correlation between the disease severity and leptin level was independent of age and body mass index (10). The later studies investigated the effects of treatment on circulating leptin levels. Both continuous positive airway pressure (CPAP) therapy (11-13) and surgical treatment (14) reduced leptin levels without a significant change in body weight. This suggests other mechanisms rather than fat mass may contribute to the increased leptin in sleep apnea patients. For instance, pathophysiologic changes including hypoxemia, increased sympathetic activity, and sleep fragmentation in sleep apnea may lead to elevated leptin levels. Hypercapnia in patients with OSA syndrome was associated with increase levels of circulating leptin (15). The physiological explanation for CPAP-induced decline in leptin levels has not been fully elucidated. Nevertheless, there may be some explanations including reduced muscle sympathetic nerve activity (16) together with reduced level of stress (17), and a change in insulin responsiveness (18) following CPAP treatment. These explanations suggest that increased leptin production may be a consequence of OSA rather than being a hyperleptinemiainduced state. Besides, leptin may be, in part, responsible for development of several complications such as hypertension and cardiovascular disease in sleep apnea patients (19).

\section{Adiponectin}

Adiponectin, a multifunctional adipokine produced mainly by adipocytes, stimulates fatty acid oxidation, suppresses inflammatory responses and hepatic gluconeogenesis (20). In contrast to leptin and most other adipokines, adiponectin is reduced in obesity and increased in response to weight loss. Furthermore, peripheral adiponectin treatment decreases weight and fat by increasing energy expenditure and fatty acid oxidation (21). Adiponectin levels correlate inversely with insulin resistance. Adiponectin-deficient mice develop insulin resistance, dyslipidemia, and atherosclerosis (22). Several studies found decreased circulating levels of adiponectin in patients with OSA syndrome (23-27, 29); these may contribute to the development of cardio- 
metabolic complications in OSA patients. Harsh et al (23) found a significant relation between adiponectin and the insulin sensitivity index in overweight patients with OSA. During CPAP treatment, changes in adiponectin levels were highly predictable by the insulin sensitivity index. However, they failed to observe significant changes after 3 months treatment. Vatansever et al (27) suggested that recurrent hypoxia-reoxygenation attacks in OSA patients may activate oxidative stress, elevating sympathetic activity and leading to low levels of adiponectin. On the contrary, one study reported that plasma adiponectin levels were elevated in otherwise healthy subjects with OSA (28).

\section{Resistin}

Circulating resistin levels were studied in patients with OSA and obtained results seem contradictory. One of the earliest studies reported that resistin levels remained unchanged after 8 weeks of CPAP therapy and there was a weak negative correlation between insulin sensitivity index and resistin in obese OSA patients (30). However, this study did not include an OSAnegative control group and no chance to compare resistin levels between the patients and controls. In a following study, Yamamoto et al (31) measured resistin levels in 31 men with OSA and 10 men without OSA. These two groups were matched for age, body mass index and metabolic profile. The authors reported that untreated OSA patients had a higher mean serum resistin level than control subjects and 3 months CPAP therapy led to reduction in resistin levels in the patient group. On the contrary, Ursavas et al (32) found no significant difference in circulating resistin levels in OSA group compared to non-OSA controls, whereas decreased resistin levels in overweight and obese subjects with OSA were reproted (33).

Collectively, all these studies on secretory products of adipocytes show us that adipocyte function alters during the course of sleep apnea syndrome. Yet it is not clear whether those changes are consequences resulting from or causes leading to the disease. Investigating the mechanisms of adipose tissue dysfunction in patients with OSA may provide us with novel targets to prevent its complications and also the disease itself (for resistin-targeted pharmacotherapy, see Gertler's innovative review in this volume of Adipobiology).

In the following section, the plausible mechanisms of adipose dysfunction will be discussed.

\section{MECHANISMS OF ADIPOSE DYSFUNCTION IN OBSTRUCTIVE SLEEP APNEA}

Hypoxia

Hypoxia is one of the hallmarks of OSA. Recurrent episodes of apnea or hypopnea are followed by marked transient decreases in arterial oxygen saturation. By the resumption of ventilation, blood oxygen saturation rapidly turns to normal levels. This kind of hypoxia is called as intermittent hypoxia which may be quite distinct from sustained hypoxia mostly seen in chronic obstructive lung diseases. In addition to fluctuating arterial oxygen saturation during nighttime due to apneic episodes of sleep, adipose tissue may be affected from a daytime hypoxia stemming from obesity itself. Trayhurn (34) stated that cardiac output and blood flow to adipose tissue are not increased in proportion to fat mass in obesity. Second, diameter of adipocytes may increase up to $150-200 \mathrm{~mm}$ and this is larger than normal diffusion distance of oxygen (i.e., 100-200 mm) (34). Taken together, both respiratory cessations and obesity contribute to hypoxia which may affect the secretory function of adipocytes. In fact, it has been shown that hypoxia inhibited the expression and secretion of adiponectin in 3T3-L1 cell line which differentiate into an adipocyte-like phenotype (35). Human adipocytes were also incubated in either $21 \%$ or $1 \%$ oxygen for $24 \mathrm{~h}$ and hypoxic state led to increase in adipokines including leptin, vascular endothelial growth factor, and interleukine-6 release (34). Finally, transcription factors including nuclear factor kappa $\mathrm{B}(\mathrm{NF} \kappa \mathrm{B})$ and hypoxia inducible factor (HIF)-1 implicated in the molecular response to hypoxia are activated in adipocytes. Studies in patients with OSA showed NFkB activation in circulating monocytes and neutrophils (36). No previous study investigated NFKB in adipocytes obtained from OSA patients. However, strong evidence suggest hypoxia as one of the main factors affecting adipokine production.

\section{Oxidative stress}

It is plausible to consider that hypoxia/reoxygenation episodes during apneas and hypopneas may lead to increased oxydative stress, and besides hypoxia, oxidative stress may contribute to adipocyte dysfunction in sleep apnea syndrome. However, the presence of oxidative stress in sleep apnea patients is controversial. Several studies reported increased oxidative stress in patients with obstructive slep apnea. For instance, morning levels of oxidative stress biomarkers such as thiobarbituric acid reactive substances and peroxides significantly increased in patients with OSA (37). Superoxide generation from polymorphonuclear neutrophils was enhanced in OSA and effective CPAP treatment fully reversed superoxide release (38). Conversely, some other studies failed to find any evidence of increased oxidative stress in OSA (39-41). Oxidative stress may affect adipocyte physiology. Kamigaki et al (42) examined the effect of hydrogen peroxide on the gene expressions of adiponectine, leptin and resistin. These latter authors suggested that even short-time exposure to oxidative stress was enough to change expression of some adipokines for a long time. 


\section{Increased sympathetic nerve activity}

Adipose tissue is innervated by the sympathetic nervous system. Both in vitro and in vivo studies demonstrated that norepinephrine stimulation of WAT via b-adrenoceptors is one of the major stimulators of lipolysis (43). Both catecholamines from adrenal medulla and norepinephrine from sympathetic innervation are important in directing lipolysis (44). Patients with OSA have a high level of sympathetic nerve activity due to increased respiratory effort and arousals during sleep, and sympathetic hyperactivity maintains even during daytime (45). Sympathetic activity may affect endocrine activity of the adipose cells besides metabolic function, and may thus alter adipokine secretion.

Regional body fat deposition i.e. central obesity appears important in OSA. The central form of obesity contributes to accumulation of adipose tissue around the upper airway and neck which in turn reduces the diameter of upper airway and promotes pharyngeal collapse (46). Understanding the factors affecting preferential fat deposition and mobilization may shed light on elucidating the pathophysiology of airway obstruction in sleep apnea. One mechanism may be the differential accumulation of lipid by adipocytes through innervation by the sympathetic nervous system (47).

\section{All roads lead to inflammation}

Although the etiology of OSA is uncertain, intense local and systemic inflammation are present in these patients. Hypoxia, oxidative stress, and sympathetic nervous activity may contribute to development of inflammation and adipocytes seem to occupy the center of these pathophysiologic pathways (Fig. 1). The presence of systemic inflammation is characterized by elevated levels of certain potent pro-inflammatory mediators such as CRP, leptin, TNF-a, IL-1b, IL-6, and reactive oxygen species. C-reactive protein is a sensitive marker for systemic inflammation. Activated $\mathrm{NF} \kappa \mathrm{B}$ is a key transcription factor in chronic inflammatory diseases. Yamauchi et al (48) have demonstrated that there was an activation of NFKB in peripheral blood monocytes, as a representative transcription factor involved in regulating inflammation, and there was evidence showing that this activation was functionally reversed by one night of CPAP titration. Apnea-induced hypoxia and reoxygenation, which generates reactive oxygen species, suggested to activate the oxidant-sensitive, $\mathrm{NF \kappa B}$, increasing systemic inflammation in OSA (36). As discussed, adipose cells can secrete both pro- and anti-inflammatory adipokines (3-7). In Homo obesus, secretory profile of adipose tissue is changed towards a proinflammatory pattern, which may contribute to the development of various diseases including OSA syndrome.

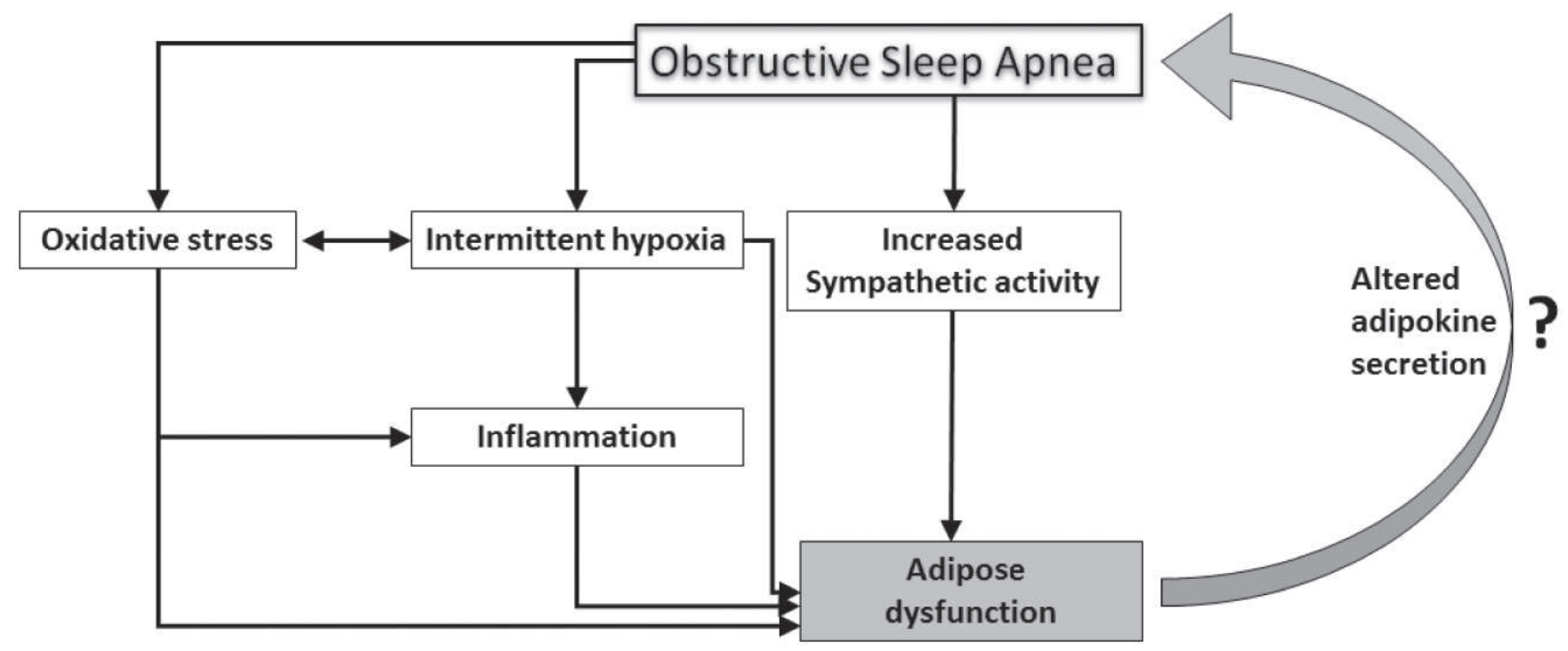

Figure 1. Mechanisms of adipose dysfunction in obstructive sleep apnea. Hypoxia and oxidative stress stemming from sleep disordered breathing lead to inflammation which collectively resulted in adipose dysfunction manifested by altered adipokine secretion, which may contribute to the pathophysiology and cardiometabolic complications in obstructive sleep apnea. 


\section{Involvement of neurotrophins}

One of biggest recent achievements of neurobiology is the study on neurotrophic factors and the role they play in the pathogenesis of various neurological and non-neurological diseases. The neurotrophins are exciting examples of these factors. They belong to a family of proteins consisting of nerve growth factor (NGF), brain-derived neurotrophic factor (BDNF), neurotrophin-3 (NT-3), NT-4/5, NT-6, and NT-7. Today, NGF and $\mathrm{BDNF}$ are well recognized to mediate multiple trophobiological effects, ranging from neurotrophic through immunotrophic and epitheliotrophic to metabotrophic effects (reviewed in 49-51). In the same vein, recent studies in adipobiology reveal that this tissue, as mentioned above, is the body's largest endocrine and paracrine organ producing multiple adipokines, with NGF and BDNF being also produced from adipose tissue (52).

Recently, some neurotrophins, particularly BDNF, enter the picture of OSA syndrome (53-59), thus providing novel pharmacological targets for the therapy of this syndrome (Trk A, Trk B receptors for NGF and BDNF, respectively). Serum and plasma BDNF levels in both pediatric and adult patients with untreated OSA syndrome were comparable to healthy peers $(54,60)$. Interestingly, treatment of OSA by adenotonsillectomy in pediatric patients (54) or by CPAP in adults (60) led to significant decrease in circulating BDNF levels. Staats et al (60) suggested that immediate BDNF decrease following treatment reflects increased neuronal demand for BDNF and changed neuronal activity and synaptic transmission. Altered BDNF regulation may be associated with neurocognitive dysfunction in patients with OSA (56).

\section{Coda}

The following main concusions might be extrcated form the present review: (i) preventing and treating OSA is a major public health priority, but compliance to CPAP therapy is low, (ii) altered adipokine secertion homeostasis may provide a new focus for understanding and potentially treating OSA and its cardiometabolic consequences, (iii) reversing hypoxia and attenuating oxidative stress and inflammation through HIFs or other regulatory factors present novel opportunities and targets in OSA therapy, (iv) Trk A and Trk B receptor-directed pharmacology may be an additional therapeutic perspective.

\section{References}

1. Vgontzas AN, Bixler EO, Chrousos GP. Metabolic disturbances in obesity versus sleep apnoea: the importance of visceral obesity and insulin resistance. J Intern Med 2003; 254: 32-44. DOI: 10.1046/j.1365-2796.2003.01177.x

2. Vgontzas AN, Bixler EO, Chrousos GP. Sleep apnea is a manifestation of the metabolic syndrome. Sleep Med Rev 2005; 9:
211-224. DOI:10.1016/j.smrv.2005.01.006

3. Chaldakov GN, Neşe Tuncel N, Beltowski J, Fiore M, Ranćić G, Tonchev A, Panayotov P, et al. Adipoparacrinology: an emerging field in biomedical research. Balkan Med J 2012; 29: 2-9. DOI: 10.5152/balkanmedj.2012.022

4. Frühbeck G, Gomez-Ambrosi J, Muruzabal FJ, Burrell MA. The adipocyte: a model for integration of endocrine and metabolic signaling in energy metabolism regulation. Am J Physiol Endocrinol Metab 2001; 280: E827-E847.

5. Töre F, Tonchev AB, Fiore M, Tunçel N, Atanassova P, Aloe L, Chaldakov GN. From adipose tissue protein secretion to adipopharmacology of disease. Immun Endoc Metab Agents Med Chem 2007; 7: 149-155.

6. Zhang YY, Proenca R, Maffei M, Barone M, Leopold L, Friedman JM. Positional cloning of the mouse obese gene and its human homologue. Nature 1994; 372: 425-432.

7. Renes J. The role of proteomics research in discovering adipocyte-secreted proteins and their (patho) physiological role. Adipobiology 2012; 4: 33-40

8. Phillips BG, Kato M, Narkiewicz K, Choe I, Somers VK. Increases in leptin levels, sympathetic drive, and weight gain in obstructive sleep apnea. Am J Physiol Heart Circ Physiol 2000; 279: H234-H237.

9. Shimizu K, Chin K, Nakamura T, Masuzaki H, Ogawa Y, Hosokawa $\mathrm{R}$, et al. Plasma leptin levels and cardiac sympathetic function in patients with obstructive sleep apnoea-hypopnoea syndrome. Thorax 2002; 57: 429-434. DOI:10.1136/ thorax.57.5.429

10. Ozturk L, Unal M, Tamer L, Celikoglu F. The association of the severity of obstructive sleep apnea with plasma leptin levels. Arch Otolaryngol Head Neck Surg 2003; 129: 538-540. DOI:10.1001/archotol.129.5.538.

11. Harsch IA, Konturek PC, Koebnick C, Kuehnlein PP, Fuchs FS, Schahin SP, et al. Leptin and ghrelin levels in patients with obstructive sleep apnoea: effect of CPAP treatment. Eur Respir J 2003; 22: 251-257. DOI: 10.1183/09031936.03.00010103

12. Sanner BM, Kollhosser P, Buechner N, Zidek W, Tepel M. Influence of treatment on leptin levels in patients with obstructive sleep apnoea. Eur Respir J 2004; 23: 601-604. DOI:10.118 3/09031936.04.00067804

13. Cuhadaroglu C, Utkusavas A, Ozturk L, Salman S, Ece T. Effects of nasal CPAP treatment on insulin resistance, lipid profile, and plasma leptin in sleep apnea. Lung 2009; 187: 75-81. DOI: 10.1007/s00408-008-9131-5

14. Lin CC, Wang YP, Lee KS, Liaw SF, Chiu CH. Effect of uvulopalatopharyngoplasty on leptin and endothelial function in sleep apnea. Ann Otol Rhinol Laryngol 2014; 123: 40-46. DOI: $10.1177 / 0003489414521385$ 
15. Shimura R, Tatsumi K, Nakamura A, Kasahara Y, Tanabe N, Takiguchi Y, et al. Fat accumulation, leptin, and hypercapnia in obstructive sleep apnea-hypopnea syndrome. Chest 2005; 127: 543-549. DOI:10.1378/chest.127.2.543

16. Snitker S, Pratley RE, Nicolson M, Tataranni PA, Ravussin E. Relationship between muscle sympathetic nerve activity and plasma leptin concentration. Obes Res 1997; 5: 338-340.

17. Heiman MI, Ahima LS, Craft B, Schoner B, Stephens TW, Flier JS. Leptin inhibition of the hypothalamic-pituitaryadrenal axis in response to stress. Endocrinology 1997; 138: 3859-3863.

18. Kapsimalis F, Varouchakis G, Manousaki A, Daskas S, Nikita D, Kryger M, et al. Association of sleep apnea severity and obesity with insulin resistance, C-reactive protein, and leptin levels in male patients with obstructive sleep apnea. Lung 2008; 186: 209-217. DOI: 10.1007/s00408-008-9082-x

19. McArdle N, Hillman D, Beilin L, Watts G. Metabolic risk factors for vascular disease in obstructive sleep apnea: a matched controlled study. Am J Respir Crit Care Med 2007; 175: 190-195. DOI: 10.1164/rccm.200602-270OC

20. Yamauchi T, Kamon J, Minokoshi Y, Ito Y, Waki H, Uchida $\mathrm{S}$, et al. Adiponectin stimulates glucose utilization and fatty acid oxidation by activating AMP-activated protein kinase. Nat Med 2002; 8: 1288-1295. DOI:10.1038/nm788

21. Ahima RS. Central actions of adipocyte hormones. Trends Endocrinol Metab 2005; 16: 307-313.

22. Maeda N, Shimomura I, Kishida K, Nishizawa H, Matsuda $\mathrm{M}$, Nagaretani $\mathrm{H}$, et al. Diet-induced insulin resistance in mice lacking adiponectin/ACRP30. Nat Med 2002; 8: 731737. DOI:10.1038/nm724

23. Harsch IA, Wallaschofski H, Koebnick C, Schahin SP, Hahn $\mathrm{EG}$, Ficker $\mathrm{JH}$, et al. Adiponectin in patients with obstructive sleep apnea syndrome: Course and physiological relevance. Respiration 2004; 71: 580-586. DOI:10.1159/000081758

24. Masserini B, Morpurgo PS, Donadio F, Baldessari C, Bossi $\mathrm{R}$, Beck-Peccoz P, et al. Reduced levels of adiponectin in sleep apnea syndrome. J Endocrinol Invest 2006; 29: 700705. DOI: 10.1007/BF03344179

25. Zhang XL, Yin KS, Hui M, Wang H, Yu Y. Serum adiponectin level in patients with obstructive sleep apnea hypopnea syndrome. Chinese Med J 2004; 117: 1603-1606.

26. Zhang XL, Yin KS, Wang H, Su S. Serum adiponectin levels in adult male patients with obstructive sleep apnea hypopnea syndrome. Respiration 2006; 73: 73-77. DOI:10.1159/000088690

27. Vatansever E, Surmen-Gur E, Ursavas A, Karadag M. Obstructive sleep apnea causes oxidative damage to plasma lipids and proteins and decreases adiponectin levels. Sleep
Breath 2010; 15: 275-282. DOI:10.1007/s11325-010-0378-8

28. Wolk R, Svatikova A, Nelson CA, Gami AS, Govender K, Winnicki M, et al. Plasma levels of adiponectin, a novel adipocyte-derived hormone, in sleep apnea. Obesity Res 2005; 13: 186-190.

29. Mutairi SA, Mojiminiyi OA, Alawi AA, Rammah TA, Abdella N. Study of leptin and adiponectin as disease markers in subjects with obstructive sleep apnea. Disease Markers 2014; Article ID 706314. DOI: 10.1155/2014/706314

30. Harsch IA, Koebnick C, Wallaschofski H, Schahin SP, Hahn EG, Ficker JH, et al. Resistin levels in patients with obstructive sleep apnoea syndrome - the link to subclinical inflammation. Med Sci Monit 2004; 10: CR510-515.

31. Yamamoto Y, Fujiuchi S, Hiramatsu M, Nishigaki Y, Takeda A, Fujita Y, et al. Resistin is closely related to systemic inflammation in obstructive sleep apnea. Respiration 2008; 76: 377-383. DOI: 10.1159/000141866

32. Ursavas A, Ilcol YO, Nalci N, Karadag M, Ege E. Ghrelin, leptin, adiponectin, and resistin levels in sleep apnea syndrome: Role of obesity. Ann Thorac Med 2010; 5: 161-165. DOI: $10.4103 / 1817-1737.65050$

33. Wysocka E, Cofta S, Dziegielewska S, Gozdzik J, Torlinski L, Batura-Gabryel H. Adipocytokines in sleep apnea syndrome. Eur J Med Res 2009; 14(Suppl IV): 255-258. DOI: 10.1186/2047-783X-14-S4-255

34. Trayhurn P. Hypoxia and adipose tissue function and dysfunction in obesity. Physiol Rev 2013; 93: 1-21. DOI: 10.1152/physrev.00017.2012

35. Chen B, Lam KSL, Wang Y, Wu D, Lam MC, Shen J, et al. Hypoxia dysregulates the production of adiponectin and plasminogen activator inhibitor-I independent of reactive oxygen species in adipocytes. Biochem Biophys Res Commun 2006; 341: 549-556. DOI: 10.1016/j.bbrc.2006.01.004

36. Htoo AK, Greenberg H, Tongia S, Chen G, Henderson T, Wilson $\mathrm{D}$, et al. Activation of nuclear factor $\kappa \mathrm{B}$ in obstructive sleep apnea: a pathway leading to systemic inflammation. Sleep Breath 2006; 10: 43-50. DOI: 10.1007/s11325-005-0046-6

37. Lavie L, Vishnevsky A, Lavie P. Evidence for lipid peroxidation in obstructive sleep apnea. Sleep 2004; 27: 123-128.

38. Schulz R, Mahmoudi S, Hattar K, Sibelius U, Olschewski H, Mayer K, et al. Enhanced release of superoxide from polymorphonuclear neutrophils in obstructive sleep apnea. Am J Respir Crit Care Med 2000; 162: 566-570. DOI: 10.1164/ ajrccm.162.2.9908091

39. Ozturk L, Mansour B, Yüksel M, Yalcin AS, Celikoglu F, Gokhan N. Lipid peroxidation and osmotic fragility of red blood cells in sleep-apnea patients. Clin Chim Acta 2003; 332: 83-88. DOI:10.1016/S0009-8981(03)00126-8 
40. Simiakakis M, Kapsimalis F, Chaligiannis E, Loukides S, Sitaras N, Alchanatis M. Lack of effect of sleep apnea on oxidative stress in obstructive sleep apnea syndrome (OSAS) patients. PLoS One 2012;7(6): e39172. DOI:10.1371/journal. pone.0039172.

41. Grabska-Kobylecka I, Kobylecki A, Bialasiewicz P, Krol M, Ehteshamirad G, Kasielski M, et al. No evidence of enhanced oxidant production in blood obtained from patients with obstructive sleep apnea. J Neg Res BioMed 2008;7:10. DOI:10.1186/1477-5751-7-10

42. Kamigaki M, Sakaue S, Tsujino I, Ohira H, Ikeda D, Itoh $\mathrm{N}$, et al. Oxidative stress provokes atherogenic changes in adipokine gene expression in 3T3-L1 adipocytes. Biochem Biophys Res Commun 2006; 339: 624-632. DOI:10.1016/j. bbrc.2005.11.059

43. Carpene C, Bousquet-Melou A, Galitzky J, Berlan M, Lafontan M. Lipolytic effects of beta 1 , beta 2, beta 3-adrenergic agonists in white adipose tissue of mammals. Ann NY Acad Sci 1998; 839: 186-189. DOI: 10.1111/j.1749-6632.1998.tb10756.x

44. Romijn JA, Fliers E. Sympathetic and parasympathetic innervation of adipose tissue: metabolic implications. Curr Opin Clin Nutr Metab Care 2005; 8: 440-444.

45. Shamsuzzaman ASM, Gersh BJ, Somers VK. Obstructive sleep apnea: implications for cardiac and vascular disease. JAMA 2003; 290: 1906-1914. doi:10.1001/jama.290.14.1906

46. Unal M, Ozturk L. The effect of body mass index on the severity of obstructive sleep apnea. In: Ferrera LA, editor. Body Mass Index and Health. Nova Science Publishers Inc. 2005; 81-96.

47. Bowers RR, Festuccia WT, Song CK, Shi H, Migliorini RH, Bartness TJ. Sympathetic innervation of white adipose tissue and its regulation of fat cell number. Am J Physiol Regul Integr Comp Physiol 2004;286:R1167-1175. doi: 10.1152/ ajpregu.00558.2003

48. Yamauchi M, Tamaki S, Tomoda K, Yoshikawa M, Fukuoka A, Makinodan K, et al. Evidence for activation of nuclear factor kappaB in obstructive sleep apnea. Sleep Breath 2006;10:189-193. doi: 10.1007/s11325-006-0074-x

49. Fiore M, Chaldakov GN, Aloe L. Nerve growth factor as a signaling molecule for nerve cells and also for the neuroendocrine-immune systems. Rev Neurosci 2009; 20: 133-145. DOI: 10.1515/REVNEURO.2009.20.2.133

50. Aloe L, Rocco ML, Bianchi P, Manni L. Nerve growth factor: from the early discoveries to the potential clinical use. J Transl Med 2012; 10: 239. PMID: 23190582 DOI: 10.1186/1479-5876-10-239
51. Yanev S, Aloe L, Fiore F, Chaldakov GN. Neurotrophic and metabotrophic potential of nerve growth factor and brainderived neurotrophic factor: Linking cardiometabolic and neuropsychiatric diseases. World J Pharmacol 2013; 2: 9299. DOI:10.5497/wjp.v2.i4.92

52. Sornelli F, Fiore M, Chaldakov GN, Aloe L. Adipose tissue derived nerve growth factor and brain-derived neurotrophic factor: results from experimental stress and diabetes. Gen Physiol Biophys 2009; 28: 179-183. PMID: 19893098

53. Goldbart AD, Mager E, Veling MC, Goldman JL, Kheirandish-Gozal L, Serpero LD, et al. Neurotrophins and tonsillar hypertrophy in children with obstructive sleep apnea. Pediatr Res 2007; 62: 489-494. DOI: 10.1203/ PDR.0b013e31814257ed

54. Wang Y, Wang JJ, Zhao MQ, Li YZ. Changes of serum brainderived neurotrophic factor in children with obstructive sleep apnoea-hypopnoea syndrome following adenotonsillectomy. J Int Med Res 2010; 38:1942-1951.

55. Xie H, Leung KL, Chen L, Chan YS, Ng PC, Fok TF, et al. Brain-derived neurotrophic factor rescues and prevents chronic intermittent hypoxia-induced impairment of hippocampal long-term synaptic plasticity. Neurobiol Dis 2010; 40:155-162. DOI: 10.1016/j.nbd.2010.05.020

56. Wang WH, He GP, Xiao XP, Gu C, Chen HY. Relationship between brain-derived neurotrophic factor and cognitive function of obstructive sleep apnea/hypopnea syndrome patients. Asian Pac J Trop Med 2012; 5:906-910. DOI: 10.1016/ S1995-7645(12)60169-2.

57. Xie H, Yung WH. Chronic intermittent hypoxia-induced deficits in synaptic plasticity and neurocognitive functions: a role for brain-derived neurotrophic factor. Acta Pharmacol Sin 2012; 33:5-10. DOI: 10.1038/aps.2011.184

58. Panaree B, Chantana M, Wasana S, Chairat N. Effects of obstructive sleep apnea on serum brain-derived neurotrophic factor protein, cortisol, and lipid levels. Sleep Breath 2011; 15:649-656. DOI: 10.1007/s11325-010-0415-7

59. Zhang J, Guo X, Shi Y, Ma J, Wang G. Intermittent hypoxia with or without hypercapnia is associated with tumorigenesis by decreasing the expression of brain derived neurotrophic factor and miR-34a in rats. Clin Med J (Engl) 2014; 127:43-47.

60. Staats R, Stoll P, Zingler D, Virchow JC, Lommatzsch M. Regulation of brain-derived neurotrophic factor (BDNF) during sleep apnoea treatment. Thorax 2005; 60:688-692. 